\title{
Response to the hunt for the perfect biomarker in nasopharyngeal carcinoma - the RRAS "race" beyond Epstein-barr virus?
}

\author{
Ruowen Xiao, Shijuan Mai \\ State Key Laboratory of Oncology in South China, Collaborative Innovation Center for Cancer Medicine, Guangdong Key Laboratory of \\ Nasopharyngeal Carcinoma Diagnosis and Therapy, Sun Yat-sen University Cancer Center, Guangzhou 510060, China \\ Correspondence to: Professor Shijuan Mai. State Key Laboratory of Oncology in South China, Collaborative Innovation Center for Cancer Medicine, \\ Guangdong Key Laboratory of Nasopharyngeal Carcinoma Diagnosis and Therapy, Sun Yat-sen University Cancer Center, 651 East Dongfeng \\ Road, Guangzhou 510060, China. Email: maishj@sysucc.org.cn. \\ Response to: Tan MTL, Wee JTS, Chua MLK. The hunt for the perfect biomarker in nasopharyngeal carcinoma-the RRAS "race" beyond Epstein- \\ Barr virus? Transl Cancer Res 2019;8:1659-62.
}

Submitted Sep 23, 2018. Accepted for publication Sep 29, 2019.

doi: $10.21037 /$ tcr.2019.10.01

View this article at: http://dx.doi.org/10.21037/tcr.2019.10.01

We sincerely appreciate Mark T. L. TAN and his coworkers for their comments "The Hunt for the Perfect Biomarker in Nasopharyngeal Carcinoma-the RRAS "race" beyond Epstein-Barr virus?" on our study titled "Identification of RRAS gene related to nasopharyngeal carcinoma based on pathway and network-based analyses". Nasopharyngeal carcinoma (NPC) is an endemic tumor closely associated with Epstein barr virus (EBV) (1). EBV infection is detected in almost $100 \%$ of non-keratinizing nasopharyngeal carcinomas (NPCs) (2,3). Recent studies have suggested that EBV DNA level in the plasma is correlated to the prognosis of patients with NPC (4). Despite the continuing identification of NPC related biomarkers, EBV-associated antigens and cfEBV DNA (cell free EBV DNA) tests remain to be the optimal choice for NPC patients. Nevertheless, because of the prevalence of EBV infection in the population, it makes sense to look for more specific biomarkers to improve the assessment of prognosis.

In our study, we introduced a bioinformatics strategy to find new potential biomarkers for NPC. We found that PI3K-Akt signaling pathway plays an important role in our pathway crosstalk analysis, and one of the hub genes PIK3CA had been reported to be amplified in NPC. Our findings are consistent with previous studies, which indicated the reliability of our strategy (2). Ultimately, we found RRAS may be associated with PIK3CA. Although putative homologs have been found interacting in other species, the interaction between RRAS and PIK3CA in human needs experimental verification.

We found that RRAS was down-regulated in NPC and associated with advanced clinical stages of NPC patients. However, the expression of RRAS showed no significant correlation with distant metastasis and regional recurrence. The combination of RRAS and cfEBV DNA might be helpful in predicting the prognosis of NPC patients, but more powerful biomarkers are needed to complement the existing tools. Considering the feasibility of the tests, detection of circulating tumor DNA or non-coding RNA in plasma might be a promising direction (5-7).

As Tan et al. mentioned, R-Ras was originally identified as an oncogene, however, accumulated evidence has suggested a tumor suppressor role for R-Ras (8). Recent study showed that RRAS is downregulated in tumor vasculature and could inhibit VEGFR activation (8-10). Besides, as lymphocyte infiltration is extensive in NPC, altered expression of R-Ras may affect the functions of immune cells associated with tumor and exert their antitumor effect $(11,12)$. Although the role of RRAS in NPC remains to be elucidated, the strategy of our research is helpful to find more potential genes associated with NPC and reveal its pathogenesis.

\section{Acknowledgments}

Funding: None. 


\section{Footnote}

Provenance and Peer Review: This article was commissioned by the Editorial Office of Translational Cancer Research. This article did not undergo external peer review.

Conflicts of Interest: Both authors have completed the ICMJE uniform disclosure form (available at http://dx.doi. org/10.21037/tcr.2019.10.01). RX reports grants from National Natural Science Foundation of China, outside the submitted work; SM reports grants from National Natural Science Foundation of China, outside the submitted work.

Ethical Statement: The authors are accountable for all aspects of the work in ensuring that questions related to the accuracy or integrity of any part of the work are appropriately investigated and resolved.

Open Access Statement: This is an Open Access article distributed in accordance with the Creative Commons Attribution-NonCommercial-NoDerivs 4.0 International License (CC BY-NC-ND 4.0), which permits the noncommercial replication and distribution of the article with the strict proviso that no changes or edits are made and the original work is properly cited (including links to both the formal publication through the relevant DOI and the license). See: https://creativecommons.org/licenses/by-nc-nd/4.0/.

\section{References}

1. Chen YP, Chan ATC, Le QT, et al. Nasopharyngeal carcinoma. Lancet 2019;394:64-80.

2. Tsao SW, Tsang CM, Lo KW. Epstein-Barr virus infection and nasopharyngeal carcinoma. Philos Trans R Soc Lond B Biol Sci 2017;372:20160270.

Cite this article as: Xiao R, Mai S. Response to The Hunt for the Perfect Biomarker in Nasopharyngeal Carcinoma-the RRAS "race" beyond Epstein-barr virus? Transl Cancer Res 2019;8(6):2506-2507. doi: 10.21037/tcr.2019.10.01
3. Tsang CM, Tsao SW. The role of Epstein-Barr virus infection in the pathogenesis of nasopharyngeal carcinoma. Virol Sin 2015;30:107-21.

4. Zhang J, Shu C, Song Y, et al. Epstein-Barr virus DNA level as a novel prognostic factor in nasopharyngeal carcinoma: A meta-analysis. Medicine (Baltimore) 2016;95:e5130.

5. Fiala C, Diamandis EP. Utility of circulating tumor DNA in cancer diagnostics with emphasis on early detection. BMC Med 2018;16:166.

6. He B, Zeng J, Chao W, et al. Serum long non-coding RNAs MALAT1, AFAP1-AS1 and AL359062 as diagnostic and prognostic biomarkers for nasopharyngeal carcinoma. Oncotarget 2017;8:41166-77.

7. Ferracin M, Lupini L, Mangolini A, et al. Circulating Non-coding RNA as Biomarkers in Colorectal Cancer. Adv Exp Med Biol 2016;937:171-81.

8. Liu WN, Yan M, Chan AM. A thirty-year quest for a role of R-Ras in cancer: from an oncogene to a multitasking GTPase. Cancer Lett 2017;403:59-65.

9. Sawada J, Li F, Komatsu M. R-Ras Inhibits VEGF-Induced p38MAPK Activation and HSP27 Phosphorylation in Endothelial Cells. J Vasc Res 2015;52:347-59.

10. Sawada J, Li F, Komatsu M. R-Ras protein inhibits autophosphorylation of vascular endothelial growth factor receptor 2 in endothelial cells and suppresses receptor activation in tumor vasculature. $\mathrm{J}$ Biol Chem 2015;290:8133-45.

11. Singh G, Hashimoto D, Yan X, et al. R-Ras is required for murine dendritic cell maturation and CD4+ T-cell priming. Blood 2012;119:1693-701.

12. Yan X, Yan M, Guo Y, et al. R-Ras Regulates Murine T Cell Migration and Intercellular Adhesion Molecule-1 Binding. PLoS One 2015;10:e145218. 